\title{
PARA UMA ESTÉTICA DA CRIAÇÃO DEDUÇÕES BONAVENTURIANAS DA TEORIA DO VERBO EM ANSELMO
}

Filipa Afonso

Centro de Filosofia da Universidade de Lisboa

Os mais de cem anos ${ }^{1}$ que distanciam as produções filosóficas de Anselmo e Boaventura não desbotaram a pertinência dos argumentos do primeiro, nem o entusiasmo e a reverência do segundo, perante a arquitectura racional erigida no Proslogion, no Cur Deus Homo, e no Monologion. Perfilhando, na arguição das suas próprias teses, o princípio, celebrizado pelo Monge de Le Bec, da fides quaerens intellectum impulsionador, por seu turno, de um procedimento sola ratione -, Boaventura acolhe do seu antecessor, não apenas um método e um corpo comum de temas e problemas, mas perspectivas afins que faz conjugar com uma tonalidade intelectual própria. Se, no entanto, para o Doutor Seráfico, a apropriação e a reconfiguração das provas anselmianas da existência de Deus lhe valeram, da parte de intérpretes como Pierre Rousseau, o epíteto de "melhor comentador de Santo Anselmo", a influência deste autor sobre o seu pensamento está longe de se circunscrever no espectro dessa questão.

Quando, pois, Boaventura, na distinção vinte e sete do seu Comentário às Sentenças de Pedro Lombardo, debate e esclarece o sentido próprio do conceito de "Verbo divino", é a filosofia do Monologion que convoca para a conclusão do problema e a resolução das dissensões. E será este, em rigor, o filão que procuraremos seguir, em direcção a uma teoria da criação que, nas mãos do filósofo de Bagnoregio, se dirá, por sua vez, atravessada

\footnotetext{
1 Anselmo termina a sua última obra - De Concordia Praescientiae et Praedestinationis et Gratiae Dei cum Libero Artibitrio - em 1108. Estima-se, por sua vez, que Boaventura terá redigido os seus Commentaria in Quatuor Libros Sententiarum entre os anos de 1250 e 1252.
}

Philosophica, 34, Lisboa, 2009, pp. 145-156 
por uma mundividência estética ${ }^{2}$. Mas, perscrutemos, por ora, a noção de "Verbo", conforme nos é apresentada por Anselmo e por Boaventura.

Segundo Anselmo, a exigência de perfeição do Espírito supremo - pelo qual entende a natureza de Deus - obriga à concepção de um verbo interior como termo de uma acção intrínseca de autoconhecimento. Aquele que é espírito perfeito não pode, na verdade, não inteligir ${ }^{3}$ - acto que, por seu turno, prescinde, na essência divina, do objecto externo, para, em nome da sua auto-suficiência, mergulhar numa íntima perscrutação de si, na qual Deus se firma simultaneamente como sujeito e como objecto ${ }^{4}$. Pensando-se, o Espírito supremo tece a partir de si o Verbo no qual inteiramente se exprime e que é semelhança acabada na qual o Divino se conhece. De facto, para Anselmo, como aliás para Boaventura, conhecer é proferir para si próprio, numa palavra silenciosa, o objecto do conhecimento ${ }^{5}$. Sob este prisma, da intelecção do Espírito supremo pelo Espírito supremo, engendra-se o Verbo divino que interiormente manifesta, qual imagem perfeita, esse mesmo Espírito supremo do qual emana e que representa.

Sem hesitação, Boaventura repete, em diversas páginas da sua obra, o sentido do Verbo intra-divino proposto pelo autor do Monologion. Nas suas Collationes in Hexaemeron, de resto, a autoridade de Anselmo serve de apoio à afirmação da correlatividade entre a sabedoria, o conhecimento e a geração do verbo ${ }^{6}$. O modelo cognitivo que preside à consideração anselmiana da emanação da segunda pessoa da Trindade vai-se, porém, transfigurando, no seio da filosofia do Doutor Seráfico e na esteira da

2 Das múltiplas acepções que o conceito «estética» pode assumir, elegemos, neste contexto, o seu significado de «filosofia da beleza» ou «estudo sobre a natureza do belo».

3 «Si enim nihil intelligeret, quomodo esset summa sapientia?» (Mon. 32; PL 186B, in De Divinitatis Essentia Monologium, J.-P. Migne (ed.), Patrologia Latina 158, , pp. 141-224).

4 «Aut si nullo modo esset aliquid praeter illam, quid illa intelligeret? Sed nunquid seipsam non intelligeret? » (Mon. 32; 186b).

5 «Habet igitur mens rationalis, cum se cogitando intelligit, secum imaginem suam ex se natam, id est cogitationem sui ad suam similitudinem, quasi sua impressione formatam, quamvis ipsa se a sua imagine, non nisi ratione sola, separare possit, quae imago ejus verbum ejus est.» (Mon. 33; 188a-188b). «Loqui ad se nihil aliud est quam aliquid mente concipere. Mens autem concipit intelligendo, et intelligendo aliud concipit simile alii, intelligendo se concipit simile sibi, quia intelligentia assimilatur intellecto.» (I Sent., d. 27, p. 2, a. un., q. 1; I, 482b, in Doctoris Seraphici S. Bonaventura SRE Episcopi Cardinalis. Opera Omnia, Ad Claras Aquas, Quarracchi, 1883-1902).

6 «Sapientia igitur in cognitione est; ubi autem est cognitio, necesse est, ut sit emanatio sive generatio verbi, ex qua generatione sequitur productio amoris nectentis; et sic producens est Pater, verbum est Filius, nexus Spiritus sanctus, in quibus est trinitas vere distincta, non in sapientia et in mente, sicut est in anima. Et hoc dicit Anselmus in Monologio.» (Hexaem. XI, 4; V, 380b). 
Suma Halense ${ }^{7}$, num modelo de emanação natural, segundo o qual todas as coisas produzem a partir de si a sua semelhança. Princípio este que, observado em Deus, explica racionalmente a produção da Imagem de si constituída pelo Pai e consubstanciada no Filho. Pertence pois à natureza espiritual do Divino a geração do Verbo, em analogia com a mente que, enquanto tal, conhece e, nesse sentido, engendra um conceito mental ${ }^{8}$. Ao suprimir o adjectivo "intelectual" do modo de emanação do Filho, Boaventura salvaguarda, assim, o concurso da inteligência naquele outro modo de emanação dita liberal ou voluntária - que descreve a expiração do Espírito Santo. Esquiva-se, deste modo, de a restringir à processão do Verbo e de a opor à processão por vontade, também ela delineada sob o concurso da inteligência 9 .

Ora, a ideia de que compete à natureza divina [per modum naturae] a sua integral comunicação enquadra-se, com maior pertinência, no âmbito de uma concepção de Deus como "bem difusivo de si", que Boaventura resgata da filosofia neo-platónica do Pseudo-Dionísio. Se nela, no entanto, a difusividade do bem supremo ressoava na totalidade da criação, Boaventura reintegra-a na intimidade do Divino, para aí explicar a fecundidade plena do Pai na generosa doação da sua substância ao Filho. Por isso, e porque o Bem, em Deus, designa a sua natureza, a difusão integral de si no esplendor consubstancial que é o Verbo diz-se natural ${ }^{10}$.

${ }^{7}$ Summa Theologica, I, q. 27, a. 2, in Doctoris irrefragabilis Alexandri de Hales ordinis minorum Summa Theologica I, iussu et auctoritate B. Klumper, Ad Claras Aquas, Quarracchi, 1924.

8 «Similitudo est in origine. Nam sicut Filius per modum naturae procedit per omnia Patri similis, sic verbum intellectus a mente procedit per modum naturae per omnia ei simile et aequale; unde dicitur mentis conceptus.» (I Sent., d. 27, p. 2, a. 1, q. 4; I, 490a).

9 «Ad illud quod obiicitur, quare non procedit aliqua persona per modum rationis; dicendum, quod omnis modus producendi nobilis ad istos duos reducitur; quia omne agens aut agit naturaliter, aut per voluntatem; - agens enim per violentiam, aut per fortunam est agnes imperfectum, et modus producendi minus nobilis - unde ratio non distinguitur contra naturam et voluntatem quantum ad modum agendi; et ideo non est persona tali modo procedens.» (I Sent., d. 10, a. 1, q. 1; I, 196a). Sobre este assunto, cf. BISSEN, Jean Marie, L'exemplarisme divin selon Saint Bonaventure, Paris, Vrin, 1929, pp. 117-118.

10 Esta posição vai de encontro às palavras de Bougerol, quando afirma que «La diffusion est donc en Dieu souveraine. Elle produit au sein même de Dieu les personnes par une communication toujours actuelle, naturelle parce que la Bonté en lui est sa nature [...].» (BOUGEROL, Jacques-Guy, "S. Bonaventure et le Pseudo-Denys l'Aréopagite", Actes du Colloque S. Bonaventure 9-12 Septembre 1968, Orsay, 1971, p. 104). Na verdade, o conceito de "bem difusivo" permite, à vez, pensar a emanação natural e a emanação voluntária como ordenada ao bem final. «Sicut autem visionis essentialium ipsum esse est principium radicale et nomen, per quod cetera innotescunt; sic contemplationis emanationum ipsum bonum est principalissimum fundamentum.» (Itin. VI, 1; V, 310b). 
Aqui, com efeito, adquire profundo significado a relação de sinonímia estabelecida por Boaventura no Livro Quarto do Comentário às Sentenças - que une o Bem à definição de luz ${ }^{11}$, tornando indiferenciáveis os termos que, para Platão como para o Pseudo-Dionísio, apenas se permutavam por uma transferência metafórica. O bem que, por si mesmo, se difunde, coincide, na verdade, com aquela luz que, sendo, resplandece. E o sumo bem que, por si mesmo, se difunde sumamente, coincide com aquela luz suprema que, sendo, resplandece de modo supremo ${ }^{12}$. A propriedade manifestativa da radiação luminosa, no eflúvio da sua fonte, parece, de resto, ajustar-se àquele verbo que revela o seu princípio, pela igualdade que com ele ostenta.

Mas, se, na filosofia bonaventuriana, o princípio do "bonum diffusivum sui" ganha preponderância na humana ponderação das emanações trinitárias e da geração do Filho, em particular, o nome divino "Verbo", como significante de um enunciado do conhecimento de si da Divindade, esse, permanece associado a um modelo cognitivo ${ }^{13}$. De Anselmo a Boaventura, portanto, o Verbo designa expressão semelhante ao Pai, ou melhor, igualdade perfeita porque originada da perfeição do dizer intra-divino que não admite incompletude (pela qual o Verbo se firmasse como mera imagem parcial do seu objecto), nem corrupção (pela qual subsistisse diferença essencial entre o Verbo e o seu sujeito). A expressão perfeita consagrada no Verbo distingue-se, é certo, daquele que a profe$\mathrm{re}^{14}$, mas iguala-se-lhe ao constituir-se como sua imagem íntegra ou absolutamente adequada, comungando, por isso, da mesma substância: a substância única divina ${ }^{15}$.

Reflectido no contexto da vida trinitária e como teremos oportunidade de verificar, em qualquer contexto da sua tematização, o Verbo descobre-se no seu carácter relacional em virtude de uma dupla referência:

11 «[...] bonum dupliciter potest considerari, scilicet in se, et sic dicitur lux [...].» (IV Sent., d. 18, p. 2, dubia IV; IV, 497a).

12 «Nam 'bonum dicitur diffusivum sui'; summum igitur bonum summe diffusivum est sui.» (Itin. VI, 2; V, 310b).

13 «Dicendum, quod in intellectu verbi cadunt istae conditiones, scilicet intelligentis cognitio, similitudinis concepto et alicuius expressio.» (I Sent., I, 27, p. 2, a. un., q. 3; I, 487b)

14 «Sed cum haec ita sint, miro tamen modo apertissimum est quia nec ille, cujus est Verbum, potest esse Verbum suum; nec Verbum potest esse iste cujus est Verbum [...]» (Mon. 38; 191b). Boaventura cita esta mesma passagem em I Sent., p. 2, a. un., q. 1; I, 481a.

15 «Etenim cum omnia quae de illa supra potuit animadvertere, rationis robur inflexibile teneant, illud me maxime cogit de illa diligentius discutere, quia id ipsum, quod ipse summus spiritus est, probatur esse. Si enim ille nihil fecit, nisi per seipsum, et quidquid ab eo factum est per illam est factum, quomodo illa est aliud quam quod est idem ipse?» (Mon. 29; 182c). 
ao sujeito que o origina e ao objecto ao qual se assemelha ${ }^{16}$. A reflexividade do conhecimento divino impõe a identidade entre objecto e sujeito sob a noção de uma expressão subjectiva ${ }^{17}$, segundo a qual Deus se diz a si próprio no Verbo divino. De facto, na filosofia anselmiana, a reflexividade deste Verbo nunca se suspende, mesmo quando integrado numa metafísica da criação, sob a designação de um verbo criador que acolhe em si mesmo o modelo de todo o criado. De relance, pois que aqui se trata de uma observação a superar, a perspectivação do Verbo divino desde uma teoria da criação parece fazer verter a referência objectiva deste Verbo sobre a multiplicidade das criaturas, restando ao Pai a figura do dizente. Sob este prisma, o Verbo constituir-se-ia como imagem da criação, pulverizando, assim, na diversidade, a unidade lograda pelo seu espelhamento do Pai. Em conformidade com o que Boaventura haveria de sublinhar, o conceito de "Verbo", para designar a segunda pessoa da Trindade, aufere, com efeito, especial relevância na tessitura da relação entre Deus e Criação, por força da pluralidade referencial que o define e por contraposição com a noção de "Filho", que exprime apenas comparação ao Pai ${ }^{18}$. Não é, porém, sob os moldes de uma referência objectiva que o Verbo firma a sua alusão à realidade criada. Ali onde Boaventura

16 A condição relacional do Verbo devém explícita, no seu duplo semblante, no segundo capítulo da primeira questão da obra de Maria Leonor Xavier, Razão e Ser. Três Questões de Ontologia em Santo Anselmo: «A distinção do Verbo, é, pois, uma função da sua condição relacional. Manifestando a plurivocidade desta condição, pode dizer-se que o Verbo é, não só ex altero, mas também ad alterum e alterius: o Verbo é ex altero, enquanto é originado ou gerado por outro; o Verbo é ad alterum, enquanto é imagem ou semelhança de outro; o Verbo é alterius, em qualquer dos sentidos em que o mesmo é determinado por outro.» (XAVIER, Maria Leonor, Razão e Ser. Três Questões de Ontologia em Santo Anselmo (tese de Doutoramento), Lisboa, 1994, p. 177). «Verbum namque hoc ipsum quod Verbum est, aut imago, ad alterum est; quia non nisi alicujus Verbum est aut imago; et sic propria sunt haec alterius, ut nequaquam alteri coaptentur. Nam ille, cujus est Verbum aut imago nec imago, nec Verbum est. Constat igitur quia exprimi non potest quid duo sint, summus Spiritus et Verbum ejus, quamvis quibusdam singulorum proprietatibus cogantur esse duo. Etenim proprium unius est esse ex altero, et proprium est alterius alterum esse ex illo.» (Mon. 38; 192a), ideia retomada por Boaventura em diversos lugares da segunda parte da distinção vinte e sete.

17 A expressão subjectiva opõe-se aqui a uma expressão objectiva, que consistiria na imagem de um objecto outro, distinto do seu sujeito. Estes conceitos estão amplamente em uso na reflexão de Maria Leonor Xavier sobre a teologia do Verbo: cf. XAVIER, Maria Leonor, op. cit., pp. 135-191.

18 «Dicendum, quod filius solum dicit comparationem ad patrem, verbum vero dicit comparationem ad dicentem, dicit comparationem ad id, quod per verbum dicitur, [...]; et cum Dei Filius debeat hic describi non tantum in comparationem ad patrem, a quo procedit, sed etiam ad creaturas, quas fecit [...]: nobilissime et decentissime sub nomine verbi describi debuit, quia nomen illud ad omnia respicit, nec posset in mundo nomen convenientius inveniri.» (Comm. Jn I, 6; VI, 247b) 
entrelaça o nome "Verbo" com a criação, esta emerge, não como o dito do Verbo divino, mas como o dito pelo Verbo divino: nuance significativa que convirá adiante destrinçar.

Ora, quando Anselmo, numa depurada incursão pela teoria da línguagem, descreve como o pensamento de determinado objecto origina na mente do sujeito pensante a imagem desse mesmo objecto, limita-se a transferir para Deus a simples consideração do mecanismo da produção da imagem, sem mencionar a exterioridade ou alteridade do objecto pensado ${ }^{19}$. É que, na perscrutação da Divindade, apenas o que lhe convém deve ser a ela reconduzido, e o movimento pelo qual Deus concebe a criação não se distingue, em substância, daquele movimento pelo qual Deus se pensa a si mesmo, para lá de uma efectiva relação ao criado. Senão vejamos: em consonância com uma exigência de racionalidade que perpassa toda a filosofia anselmiana, a criação requer, como condição da sua ordem (pela qual a multiplicidade criada se concerta numa unidade), e da sua beleza (pela qual a multiplicidade criada participa da forma divina) ${ }^{20}$, a antecedência de um exemplar na mente criadora, à semelhança do qual emerge ${ }^{21}$. Qual artesão que interiormente concebe e projecta o que posteriormente fabrica, Deus exprime no Verbo o modelo de todas as suas criaturas, com as quais estabelece, não uma relação de significante a significado, mas uma relação de exemplar a cópia que mais se coaduna com a comparação entre o Verbo interior e o verbo proferido [verbum prolatum] do que com a comparação entre o Verbo e o seu objecto, o qual confina, ainda e sempre, com o Pai ${ }^{22}$.

19 «Cum enim cogito notum mihi hominem absentem, formatur acies cogitationis meae in talem imaginem ejus qualem illam per visum oculorum in memoriam attraxi; quae imago in cogitatione, verbum est ejusdem hominis, quem cogitando dico. Habet igitur mens rationalis, cum se cogitando intelligit, secum imaginem suam ex se natam, id est cogitationem sui ad suam similitudinem, quasi sua impressione formatam, quamvis ipsa se a sua imagine, non nisi ratione sola, separare possit, quae imago ejus verbum ejus est. Hoc itaque modo, quis neget summam sapientiam, cum se dicendo intelligit, gignere consubstantialem sibi similitudinem suam, id est Verbum suum?» (Mon. 33; 188 ${ }^{\mathrm{a}}-188 \mathrm{~b}$ )

20 «[...] illa summa essentia tamen rerum molem, tam numerosam multitudinem, tam formose formatam, tam ordinate variatam, tam convenienter diversam, sola per seipsam produxit ex nihilo.» (Mon. 7; 155a)

21 «Nullo namque pacto fieri potest aliquid rationabiliter ab aliquo, nisi in facientis ratione praecedat aliquod rei faciendae quasi exemplum, sive (ut aptius dicitur) forma, vel similitudo, aut regula. Patet itaque quoniam priusquam fierent universa, erat in ratione summae naturae, quid aut qualia aut quomodo futura essent $[\ldots]$ » (Mon. 9; 157c)

22 «Propter hoc intelligendum, quod dicere idem est quod loqui; loqui autem est dupliciter, vel ad se, id est apud se, vel ad alterum. Loqui ad se nihil aliud est quam aliquid mente concipere. Mens autem concipit intelligendo, et intelligendo aliud concipit sine alii, intelligendo se concipit simile sibi, quia intelligentia assimilatur intellecto. Mens igitur dicendo se apud se concipit per omnia simile 
Se a distinção, operada pela reflexão bonaventuriana, entre o verbo concebido [verbum conceptum], como designação própria da segunda pessoa da Trindade, e o verbo proferido, como designação própria da criação, não sobrevém à consideração de Anselmo, ela permite, não obstante, explicitar um dos aspectos axiais da sua metafísica da criação. O Verbo divino, assemelhando-se ao Pai, não se assemelha, contudo, enquanto Verbo da criação, à criação, mas é esta que, em graus diversificados, se assemelha ao Verbo divino, à maneira de uma palavra proferida que procura, na voz, imitar o conceito interiormente concebido: visão que substitui, em definitivo, a ideia de uma imitação do verbo cognitivo a respeito da criatura cognoscível, consagrada num conhecimento de tipo objectivo ${ }^{23}$. Mas, sejamos rigorosos: à luz do "modelo do faber" - expressão que colhemos directamente das leituras de Maria Leonor Xavier e que trabalha a teoria anselmiana da criação sob a analogia da actividade artesã -, a criatura converte-se, efectivamente, em objecto do Verbo divino. De facto, é ela o fito daquela expressão criadora no Verbo contida. Porém, em momento algum se afirma como significado do Verbo, pois que tal transfiguraria o próprio Verbo numa semelhança da criação, permeável, portanto, à sua imperfeição e mutabilidade ${ }^{24}$. Por isso, a expressão das criaturas [rerum locutio] não abandona nunca a expressão da Divindade, da qual se diz invariavelmente imagem e que constitui, invariavelmente, o referente de significação.

Ao mesmo tempo que dissolve a consagração do Verbo como semelhança da criação divina ${ }^{25}$, o "modelo do faber" revela-se insuficiente, segundo Anselmo, na ponderação do acto criador da Divindade. Isto porque, enquanto o artesão, ao ponderar a sua criação futura, se serve de materiais pré-existentes e do conhecimento adquirido de objectos externos, Deus a nada recorre senão a si mesmo e à semelhança que de si con-

sibi; et hoc est verbum conceptum. - Alio modo dicere ad alterum est conceptum mentis exprimere; et huic dicere respondet verbum prolatum. [...]. Nam dicere Dei apud se, hoc est intelligendo concipere; et hoc est generare prolem similem sibi, et huic dicere respondet verbum natum, id est Verbum aeternum. Alio modo dicere est exterius se exprimere, et sic idem est dicere quod se per creaturam declarare, et huic dicere respondet verbum creatum et verbum temporale.» (I Sent., d. 27, p. 2, a. un., q. 1; I, 482b).

23 «Satis itaque manifestum est in Verbo, per quod facta sunt omnia, non esse eorum similitudinem, sed veram simplicemque essentiam; in factis vero non esse simplicem absolutamque essentiam, sed verae illius essentiae vix aliquam imitationem. (Mon. 31; 185b).

24 «Mentis autem sive rationalis locutionem hic intelligo, non cum voces rerum significativae cogitantur; sed cum res ipsae, vel futurae, vel jam existentes acie cogitationis in mente conspiciuntur.» (Mon. 10; 158b)

25 Neste ponto, esclarece-se a razão pela qual Boaventura afirmara que as criaturas constituem, não o dito do Verbo divino, mas aquilo que se constitui pelo Verbo divino. 
cebe, dispondo-se, assim, como causa primeira, única e suficiente da sua criação. A expressão que, dessa forma engendra, bebe apenas da própria fonte divina - razão pela qual se diz indiferenciada da substância expressiva. Pelo contrário, naquele que, planeando a sua obra, recorre à imagem de outros, a expressão distingue-se, não formando com o seu princípio uma unidade substancial26.

Quando, então, Anselmo afirma que "por um e o mesmo Verbo, [o Criador] diz-se a si mesmo $e$ tudo quanto fez"27, a cópula que aí emprega não introduz qualquer conjunção, o que faria da expressão de si e da expressão da criação uma dualidade de verbos, mas comporta, em vez disso, uma dimensão explicativa, que faz da expressão de tudo quanto foi feito um simples desdobramento do sentido já contido na expressão de si mesmo. Afinal, entendemos bem, através do conceito da simplicidade divina, que aquilo que Deus é e aquilo que Deus pode fazer não diferem na unidade da essência suprema, pelo que a expressão da criação vem incluída na auto-expressão de Deus, no Verbo como imagem, não da própria criação, mas da potência criadora do Pai, nas suas infinitas possibilidades criáveis ${ }^{28}$. Neste sentido, o Verbo desponta como o lugar da unidade indiscernível de Deus e da criação, porque aí onde o Divino integralmente se espelha, resplandece o modelo de todas as criaturas. Para Deus, portanto, a criação não representa uma efectiva alteridade, inscrevendo-se, antes, na sua intimidade expressiva. Mas, se no Verbo se dá omnímoda unidade entre Deus e a criação, de onde devém a multiplicidade criada? A resposta a esta questão, dir-nos-á Anselmo, funda-se na plurificação da semelhança em função do grau de imitação que cada criatura logra relativamente à sua essência primeira, que é o Verbo ${ }^{29}$. Desta forma desvelada, a criação exibe, por entre a sua diversidade gritante, uma unidade transversal que decorre da universal representação do Divino, conforme expresso no Verbo.

Em substância, a teoria bonaventuriana do Verbo não se distancia um milímetro da filosofia de Anselmo. Emancipa-se dela, porém, no tom estético que concede ao Verbo, por via da admissão nocional (e não de facto) da multiplicidade no seu interior. $O$ ponto da divergência inicia-se no próprio conceito de semelhança que, sendo para Anselmo unidireccional e unívoco, traduzindo unicamente a relação de imitação do Criador

26 Mon. 11-12; 159b-160c.

27 «Ergo unico eodemque Verbo dicit seipsum et cuncta quae fecit.» (Mon. 33; 187b).

28 «Nam quod dicit, verbo dicit; et verbum alicujus est verbum, id est similitudo. Sed si nihil aliud dicit quam se aut creaturam nihil dicere potest, nisi aut suo, aut ejus verbo. Si ergo nihil dicit verbo creaturae, quidquid dicit, Verbo suo dicit.» (Mon. 33; 188c)

29 Mon. 31; 183c-185c. 
pela criatura, assume, nos escritos de Boaventura, uma bidireccionalidade que faz congregar, debaixo do mesmo termo, aquela relação da criatura relativamente ao Criador e a relação de exemplaridade que vai do Criador à criatura. Por isso, se, com Anselmo, Boaventura afirma a semelhança da criação a respeito do Verbo, para lá de Anselmo, Boaventura afirma a semelhança do Verbo a respeito de Deus, não sem, no entanto, explicitar, através de adjectivos, a diferença radical que distingue as duas acepções. Ora imitativa, ora exemplar, portanto, a semelhança define, nas suas duas modalidades, a relação entre o Verbo e a criação. Em síntese, o filósofo franciscano concede ao Verbo, por um lado, o valor da semelhança, introduzindo nele a noção de um certo espelhamento da diversidade do real e, por outro, especifica como exemplar tal semelhança, reaproximando-se, por essa via, da tese anselmiana da unidade do Verbo, pelo qual todas as outras coisas se firmam como semelhanças imitativas ${ }^{30}$.

$\mathrm{Na}$ verdade, não há mais multiplicidade no Verbo bonaventuriano do que no Verbo descrito por Anselmo. Mas, a consideração do modo como a mente humana entende e vai acedendo à compreensão do Verbo divino conduz Boaventura a supor nele uma pluralidade de ideias que, não sendo embora plurais naquele Verbo que denota inflexivelmente o Pai, se intuem como plurais em virtude da pluralidade de criaturas que conota ${ }^{31}$. A variação que Boaventura introduz na teoria anselmiana do Verbo não contraria, por conseguinte, as teses deste último, mas sublinha a dimensão da multiplicidade que, em última instância, se reconduz, de forma plena, à unidade indivisa do Verbo divino. Enquanto ideia, o Verbo exprime, efectivamente, uma comparação à criatura que modela, deixando-se, por isso, multiplicar, segundo a nossa maneira de entender - ou secundum

30 «Et quia in ipso vis conceptiva concipit similitudinem, omnia circumplectentem sub intuitu uno sive aspectu, concipit sive generat unum Verbum, quod est similitudo Patris imitativa et similitudo rerum exemplativa [...].» (I Sent., d. 27, p. 2, a. un., q. 2; I, 485b); «Verbum autem non est aliud quam similitudo expressa et expressiva, concepta vi spiritus intelligentis, secundum quod se vel aliud intuetur.» (I Sent., d. 27, p. 2, a. un., q. 3; I, 488a).

31 «[...] quamvis in Deo nullus sit respectus ad creaturam a parte rei, tamen contingit, ipsam essentiam significari in respectu ad creaturam per multa nomina. $\mathrm{Nec}$ tamen nomen sive vocabulum est vanum. Intelligendum igitur est, quod hoc nomen idea significat divinam essentiam in comparatione sive in respectu ad creaturam. Idea enim est similitudo rei cognitae, quae quamvis in Deo sit absolutum, tamen secundum modum intelligendi dicit respectum medium inter cognoscens et cognitum. Et quamvis ille respectus secundum rem plus se teneat ex parte cognoscentis, quia est ipse Deus, tamen secundum rationem intelligendi sive dicendi similitudo plus se tenet ex parte cogniti. Et quoniam cognoscens est unum, et cognita sunt multa; ideo omnes ideae in Deo sunt unum secundum rem, sed tamen plures secundum rationem intelligendi sive dicendi. Unde concedendum est, omnes rationes in Deo esse unum quid, sed non unam ideam sive rationem, sed plures.» (I Sent., d. 35, a. un., q. 3; I, 608a-608b). 
rationem -, em consonância com a multiplicidade criada. Na realidade, ou secundum rem, todavia, a ideia permanece una e indistinta do Verbo como semelhança na qual Deus se conhece ${ }^{32}$.

Ora, é o vislumbramento no Verbo dessa diversidade conotada ou secundum rationem que permitirá ao Doutor Seráfico apropriar à segunda pessoa da Trindade, na esteira de Hilário, o atributo de beleza. Concedendo a tal conceito o sentido proposto por Agostinho de "aequalitas numerosa", Boaventura imputa-o ao Verbo como conjugação singular da igualdade relativa ao Pai, de que é imagem (e em virtude da qual se nomeia "verdade"), e da numerosidade relativa à criação, de que é exemplar (e em virtude da qual se nomeia "sabedoria") ${ }^{33}$. Com efeito, sob os nomes emprestados pela essência divina (porquanto próprios da unidade de Deus, mas apropriáveis a uma só pessoa), o Verbo manifesta-se, à vez, como verdade, na adequação ao princípio que representa ${ }^{34}$, e como sabedoria, na multitude de ideias que prevêem a criação ${ }^{35}$, e, simultaneamente, como beleza, na articulação última entre os dois pontos de vista, na confluência perfeita, portanto, do uno e do múltiplo.

Mas, porque o Verbo se diz beleza, e a criação semelhança do Verbo, entendemos como autêntica a afirmação bonaventuriana do belo como transcendental do ser, naquele rascunho descoberto e publicado por François Marie Henquinet ${ }^{36}$. Distendida no círculo da criação, a beleza

32 «Et ideo est alia positio, quod ideae sunt unum secundum rem. Et hoc patet sic: idea in Deo dicit similitudinem, quae est ratio cognoscendi; illa autem secundum rem est ipsa divina veritas, sicut supra monstratum est; et quia illa est una, patet, quod secundum rem omnes ideae unum sunt.» (I Sent., d. 35, a. un., q. 2, conclusio; I, 605b).

33 «Pulcritudo Filio, propter veritatem et sapientiam. Nam sapientia multitudinem idearum, veritas autem aequalitatem includit; 'pulcritudo autem nihil aliud est quam aequalitas numerosa'». (Tripl. Via III, 7, 12; VIII, 17b). A definição de beleza que Agostinho consagra no seu De Musica (VI, 13, 38) repete-se em muitas das páginas da obra completa de Boaventura. Cf. Itin. II, 5 (V, 300b); Hexaem. VI, 7 (V, 362a); I Sent., d. 31, p. 2, a. 1, q. 3 (I, 544b); Regn. Dei, 14 (V, 542b).

34 «Et haec similitudo sive Verbum est veritas. Quid est veritas secundum definitionem? 'Adaequatio intellectus et rei intellectae' [...]». (Hexaem. III, 8; V, 344b).

35 A multiplicidade de ideias aqui apontada, consonante com a citação da nota 33, não designa pluralidade senão na relação com as criaturas, de que as ideias constituem exemplar único.

36 HENQUINET, François-Marie, «Un brouillon autographe de s. Bonaventure sur le Commentaire des Sentences», Etudes Franciscaines, 44-45 (1932-1933), pp. 633$-655,59-82$. A universalidade da beleza da criação como manifestação do Divino vem, no entanto, aduzida em muitas outras passagens: «Omne bonum et pulcrum est a Deo bono; sed omnia visibilia bona sunt et pulcra [...]» (II Sent., d. 1, p. 1., a. 2, q. 1; II, 26a); «Universum enim ex ordine pulcritudinem habet, et talis est ista pulcritudo qualem decuit fieri ad ostensionem summae sapientiae [...]» (II Sent., d. 36, a. 2, q. 1; II, 848b). Cf. ainda Itin. II, 10 (V, 302a-302b). 
celebra a origem divina de todo o criado, animando-o pelo mesmo dinamismo primordial que eternamente vivifica o vínculo inter-trinitário do Verbo com o Pai. Na relação a Deus, de facto, a criação repete, na sua medida e no seu tempo, o alento de igualar o seu princípio - alento este que, na criatura, se faz esforço e se faz mutação, e que aspira, todavia, à recondução de toda a diferença multiplicativa à unidade pulcra da causa, num movimento de gradual assemelhação. Tal como a semelhança do Verbo por comparação ao Pai é, nele, razão de beleza, a semelhança da criação por comparação a Deus é, nela, razão de beleza ${ }^{37}$.

Enquanto concertação da pluralidade sob a unidade, a beleza parece penetrar e desenlaçar o nó da questão do uno e do múltiplo. Mas, aí onde a simplicidade suprema recusa na essência o diverso, e aí onde a realidade vária omite a indistinção do uno, a beleza não pode resplandecer no seu pleno significado. Naquele Verbo, porém, onde a semelhança expressa da unidade divina e a semelhança expressiva da multiplicidade criada se justapõem, a beleza descobre a sua morada primordial, por imagem da qual tudo o mais se evidencia ou se dá a ver como belo. Ora, a incursão que por estas linhas finda, e que enraíza a metafísica da criação bonaventuriana no solo fértil do Monologion anselmiano, não releva, decerto, efectiva altercação doutrinal entre as duas leituras do Verbo divino. Desvela, contudo, desde a afinidade que as aproxima, a migração da questão até à sombra de uma luz inédita, que Boaventura converte em assinatura própria e que se pauta pelo padrão estético que imprime à filosofia que faz sua.

\section{RESUMO}

Na distinção 27 do Comentário às Sentenças de Pedro Lombardo, na questão onde o sentido próprio do conceito de "Verbo" se discute e se aclara, é a autoridade do pensamento anselmiano, conforme a sua exposição nas páginas do Monologion, que Boaventura convoca para a conclusão do problema e a resolução das dissensões. Tomando, por isso, aquele texto como ponto de partida da nossa incursão sobre a filosofia do monge de Le Bec, procurar-se-á reflectir sobre o carácter mediador do Verbo no acto da criação e sobre o modo como este constitui a chave de interpretação da questão filosófica do uno e do múltiplo. É esta relação entre o uno e o múltiplo, na qual se encerra o mistério da criação, que encontrará, por seu turno, junto da filosofia do Doutor Seráfico, fortes ressonâncias estéticas, firmadas sobre uma concepção de beleza, de matriz agostiniana, que a define como "aequalitas numerosa", que o mesmo seria dizer, como unidade da multiplicidade.

37 «Ubi enim est speculum et imago et candor, necessario est repraesentatio et pulcritudo.» (Hexaem. VI, 7; V, 362a). 


\begin{abstract}
In the distinction 27 of the Commentaries on the four books of Sentences of Master Peter Lombard, in that question where the proper meaning of the concept "Word" is discussed and clarified, Bonaventure invokes the authority of the anselmian thought, as it is exposed upon the several pages of the Monologion, for the conclusion of the problem and the solution of the dissensions. Taking, therefore, such text as the starting point of our incursion on the philosophy of the monk of Le Bec, our aim is to reflect on the mediating character of the Word in the creational act, and on the way in which it becomes the interpretational key of the philosophical question of the one and the multiple. It is this relation between the one and the multiple, in which the mystery of creation is enclosed, that, in its turn, will find strong aesthetical resonances, within the philosophy of the Seraphic Doctor founded on a certain conception of beauty, of Augustinian matrix, that defines it as "aequalitas numerosa", i.e., as unity of the multiplicity.
\end{abstract}

